\title{
Development of Information Model of Forming Basic Educational Programs in the Light of Professional Competencies
}

\author{
Lilia Motaylenko, Olga Poletayeva, Sergey Lyokhin \\ FSG-fEIHPE "Pskov State University», Faculty of Informatics. Adress: pl. Lenin 2, Pskov, \\ 180000, Russia
}

\begin{abstract}
This paper describes the process of forming the basic educational programs to the professional competence of the proposed model based on a competency areas.
\end{abstract}

Keywords - information technologies, model, professional competencies.

Introduction of Federal State Educational Standards (GEF) causes the need for new approaches in the planning and organizing the educational process at a university. When developing the curriculum for particular training the higher educational institution faces the problem of its qualitative assessment.

Figure 1 shows a standard model of the educational process at the university (Higher Educational Institution - HEI). Based on the recommendations of the GEF the university forms the Main Educational Program (MEP), which includes the Base of Disciplines (BD) with a Set of Competences Recommended (SRC) and the Variable part of Disciplines with disciplines to be chosen (VD). The university independently chooses variable the sets of disciplines, and puts them into line with the set of competencies proposed by GEF; it may also introduce additional Competences (CVD).

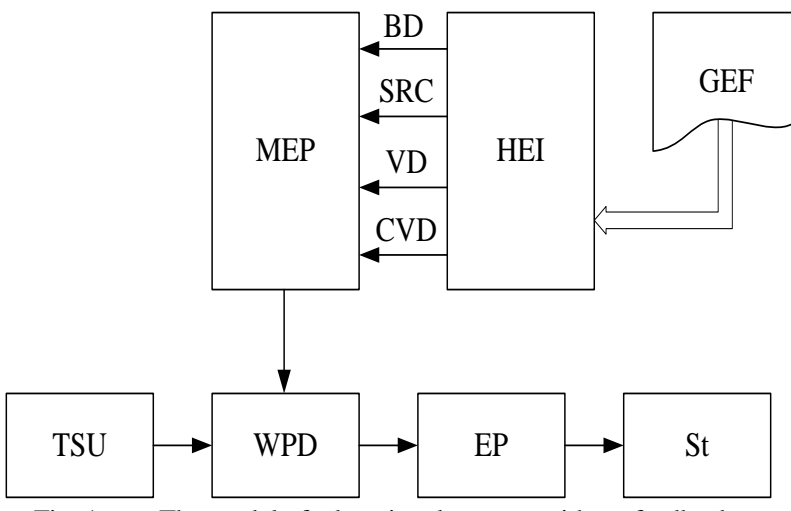

Fig. 1. The model of educational process without feedback

The competencies being acquired by the students in the course of learning disciplines from variable part are formed by the university so that they can correspond to the content of the discipline being studied. As a result a list of competences of particular training is formed which meets the requirements of GEF. On the based of MEP, developed by Teaching Staff University (TSU), Working Programs of Disciplines (WPD) are developed. The Educational Process (EP) will be organized on these programs. In this situation, the Student ( $\mathrm{St}$ ) is a consumer of education services offered by the university, without any affecting the course of the educational process.

General cultural and professional competences of future specialists are finally formed at the end of training and can't be corrected. At the same time, rapidly changing situation in the labor market requires constant monitoring and upgrading the curriculum. Therefore one should be able to change a set of competencies in subjects so that the graduate could meet the requirements both of labor market and the requirements of professional standards. [1]

To obtain practically significant result when realizing this approach a number of issues must be solved:

having learned a particular discipline students differently as for quality and quantity master competences formed by the university (the subjectivity of students);

TSU from different universities teaching the same disciplines may put qualitatively and quantitatively different competences in their courses (the subjectivity of the teacher);

the employer, when recruiting specialist, expects him/her to know how to use competencies required for a particular class of problems (the subjectivity of the employer). At the same time, the employer can not practically influence the majority of competencies obtained by the graduate, as some of them are hard-coded in the GEF, and the rest are introduced during developing the curriculum, that is, in the early phase of training the future specialist [2];

due to the possibility to introduce a variety of disciplines and competencies respectively divergent part of the cycles, different higher educational institutions can graduate specialists with slightly different skills and knowledge in the same fields (subjectivity of HEI).

The solution to these problems is possible through the implementation of upgraded models of the educational process in the institution, in particular the introduction of a feedback model and modules of 
competency areas. The latter are sets of expert assessments that take into account the contributions of competencies to the final result due to weighting coefficients. Experts can act both as developers of MED and WPD and as consumers.

It is proposed to rate competencies not only qualitatively (if a graduate holds this competence at least a little) but quantitatively (what part of educational process is dedicated to the development of competence and how well graduates hold it in general).

Figure 2 shows an educational process model that takes into account the subjectivity of a student. Based on expert assessments, competences are assigned the appropriate weight and teachers form Competence Areas (CA TSU) in their subjects. After studying the discipline the student gives expert assessment weight to competencies mastered. This results in a student's area of competence (CA St). Based on the analysis of these areas TSU make recommendations for correcting WPD both as for changing labor intensivity and as for competences being formed. The implementation of this model in the educational process may reduce the impact of subjectivity of teacher / student and increase the interest of students in obtaining of a set of knowledge and competences.

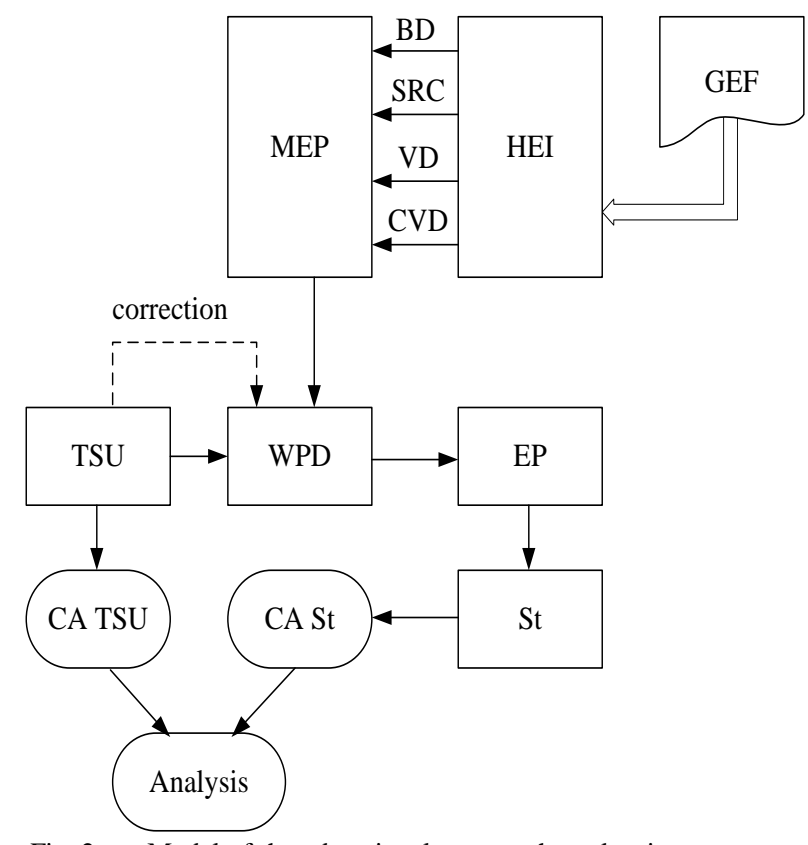

Fig. 2. Model of the educational process that takes into account the subjectivity of the student

Figure 3 shows an educational process model that takes into account the subjectivity of the Employer (Em). By analyzing either the content of the set of competencies and WPD, or MED in general, the employer creates his/her competency area (CA Em), being able to edit competences given in the GEF as well as reasonably recommend new competencies.

As it was in previous model recommendations on updating the WPD and the whole MED if there are a lot of differences and made. In the first case to make recommendations to adjust the working discipline programs, employers of different profiles may be involved. In the second case, which provides for correcting MED, the model given may be affective only when there are employers from large enterprises being competent in relevant field of training.

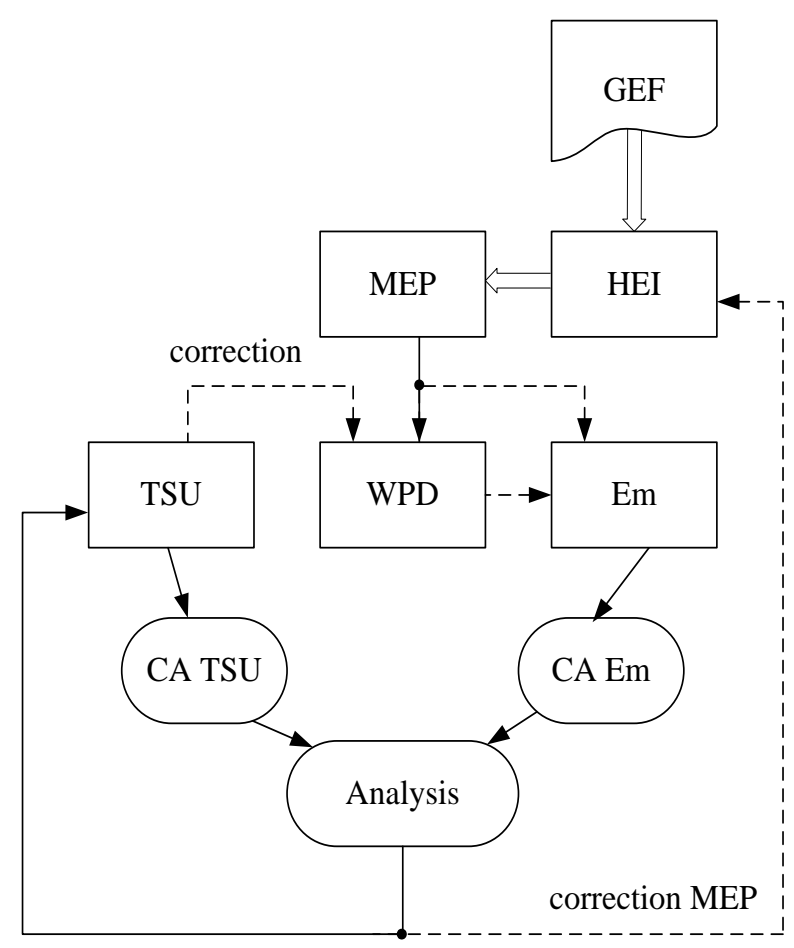

Fig. 3. Model of the educational process, taking into account the requirements of professional standards

Figure 4 shows an educational process model, which takes into account the requirements of Professional Standards (PS) for industries. In this case, the employer creates CA Em on base of professional standards and the university in it's turn creates a competence area CA based on GEF. When analyzing the differences in the requirements of the parties for competences being formed certain correction is possible in the competence area of both the employer and the university. The implementation of this model enhances the role of the employer in selecting and developing of appropriate skills.

In practice, an integrated approach is possible, that is the development of combined variants of teaching based on the model proposed.

Implementation of the proposed models of the educational process with proposed models competency areas, will provide criteria to optimize training plans and working programs while maintaining their individuality for various universities, as requirements analysis is carried out at the level of competency areas, and not of the MED, or WPD. Competency areas can be built separately for different cycles of disciplines or parts of cycles. The involvement of the employer to work at the educational process will take into account the possibility of his/her vision for the future specialist. 


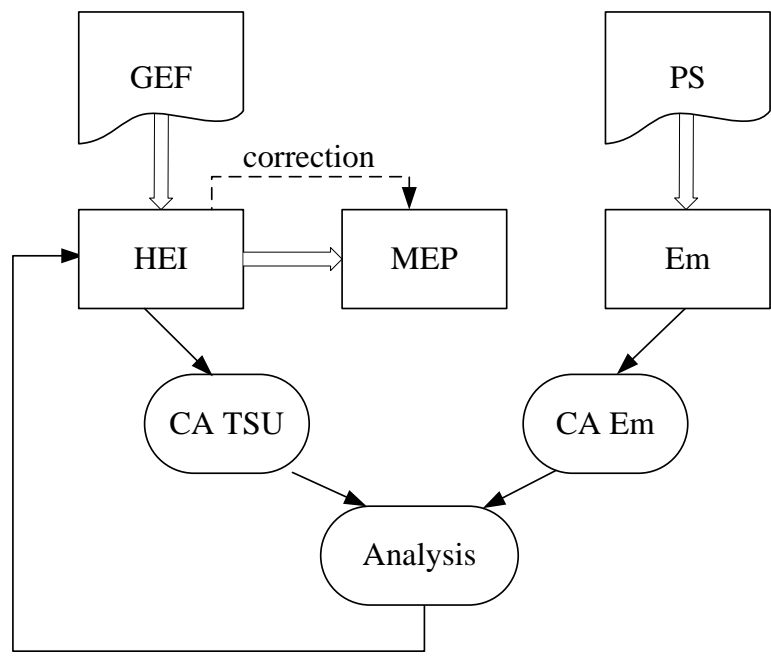

Fig. 4. Model of the educational process, taking into account the requirements of professional standards

However, practical implementation of the proposed models starting with "zero" may face a number of difficulties:

- to produce areas of competency it is necessary to gain sufficient statistical data;

- $\quad$ indifferentness to implementation of models In general, changes in the working program will be implemented only in the next academic year; employers; the objective of forming competency areas by

- $\quad$ and other difficulties.

At the same time, a number of leading universities have some achievements and positive results in implementing competence-based approach.

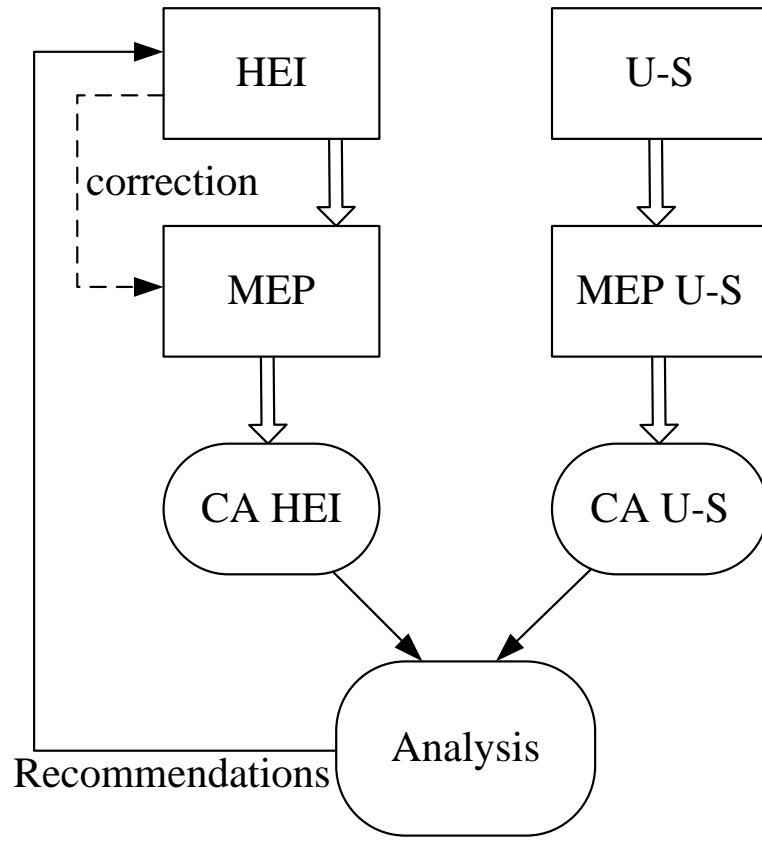

Fig. 5. Model the educational process based on the experience of leading universities

This allows on the first stage to use their findings and recommendations, that is as shown in Figure 5, to use the model, which analyzes competence areas of University-Standard (CA U-S) and a university developing and correcting MED (CA HEI), and then after accumulating necessary information to carry out the current correction of relevant documents and processes.

The implementation of the proposed models in the technology of the information system of education will decrease the effects of subjectivity when developing basic educational programs and thus increase the demand for future specialist.

To implement these models it is necessary to have a powerful tool to collect information from students, teachers and employers about competencies' weights. To satisfy this requirement, the software system was created [3].

The system consists of database (MySQL), client web application ("the client app") and desktop administration application ("the admin app") (fig. 6).

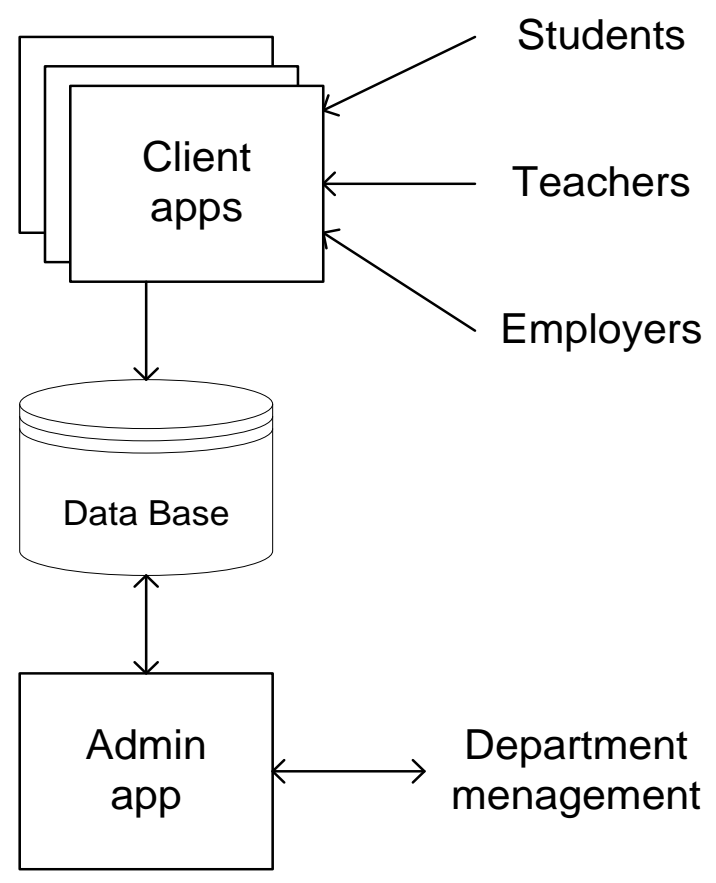

Fig. 6. Architecture of the software system

An administrator fulfills the system with lists of users, specializations, disciplines and competencies. There is an ability to automatically generate passwords. Users are grouped by roles, faculties and study years. This application created with C\# language.

To enter the client app user have to enter a password. Three roles are set: student, teacher and employer. Teacher role allows user to set list and weights of competencies of disciplines he/she teaches. Student role allows setting weights of competencies of disciplines he/she have learned. If student suggests that more competencies was purchased by him than stated in teacher's list, he can add them into his own list and rate them. Employee role allows user to set weights of competencies without separation by disciplines. Links between users and disciplines are created by administrator. This application created with PHP language and running on Apache Server. 
Collected data is performed in Admin App as 2D polar graph where angle is competence number and radius is it's weight in curriculum (fig. 7).

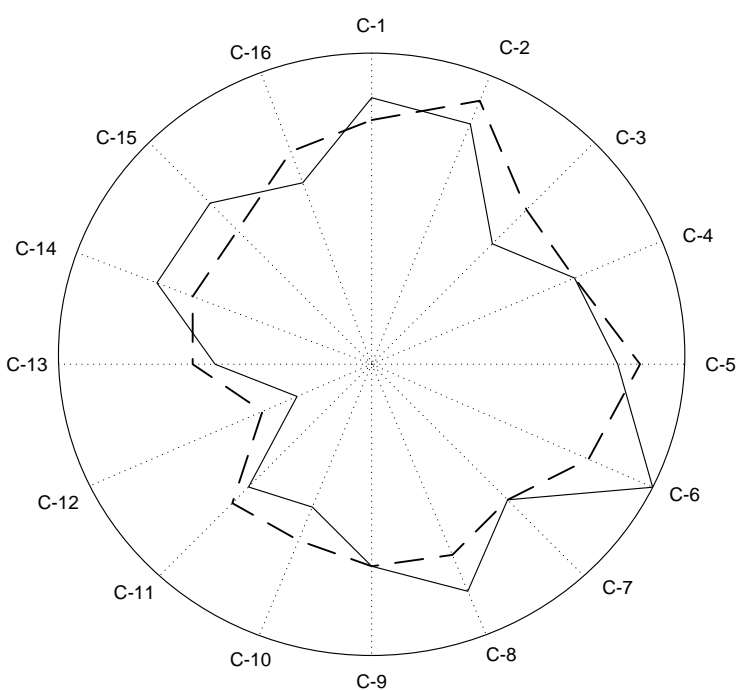

Fig. 7. Representation of CA

Solid line shows CA TCU, dot line shows CA U-S or CA Em User can select data selects from separate discipline or from curriculum in general. Competencies weights data collected from students are averaged. When user select curriculum in general, data from separate disciplines are summarized.

After data collected and results analyzed department management make decision of curriculum correction using models described above.

In models fig. 3 - fig. 5 such correction have to be make relying on desired curriculum data in general. And it is difficult with no automation. Creation of the algorithm of automation curriculum correction is one of tasks of future research.

\section{REFERENCES}

[1] Lehin S.N., Motaylenko L.V., Poletaeva O.A. MEP development in areas related to information technology to meet the requirements of professional standards for ITindustry. Education in the Russian Federation to the ten openRussian Conference (16-18 May 2012). Moscow: Moscow State University. MV University, 2012, pp. 404 - 405.

[2] Motaylenko L.V., Poletayeva O.A., Sof'ina V.N. Problem of matching the competence model of higher educational institution graduates and professional competence of the IT industry. Basic research and innovation in national research universities: Proceedings of the Scientific and Technical Conference. Vol. 4. SPb.: Izd Polytechnic. University Press, 2012. pp. 64

[3] Poletaev D.I., Poletaeva O.A., The first phase of the development of an automated information system for recording the distribution of competences // Bulletin of the Pskov State University Economic and technic since Vol.2. Pskov: Izd. Pskov SU, 2013, pp. 107 -112 